\title{
Validation and comparison of reference equations for the 6-min walk distance test
}

\author{
C.G. Cote*, C. Casanova\#, J.M. Marín ${ }^{\Uparrow}$, M.V. Lopez ${ }^{+}$, V. Pinto-Plata ${ }^{\S}$, M.M. de Oca ${ }^{f}$, \\ L.J. Dordelly*, H. Nekach* and B.R. Celli ${ }^{\S}$
}

ABSTRACT: Exercise impairment as measured by the 6-min walk distance (6MWD) test afflicts many patients with chronic obstructive pulmonary disease (COPD) and is known to predict mortality. Reference equations for the 6MWD in adults have been published but not yet validated.

The present authors prospectively followed 1,379 COPD patients for $55 \pm 30$ months and tested the predictive value of the baseline 6MWD in metres, the 6MWD work $\left(\mathrm{kg} \cdot \mathrm{m}^{-1}\right)$ and as a percentage of predicted values the 6MWD in meters according to two reference equations. Allcause mortality was the validating outcome. The best threshold values were identified for each of the tests using receiver operating characteristic (ROC) curves.

The threshold values obtained were: $350 \mathrm{~m}$ for the $6 \mathrm{MWD}, 25,000 \mathrm{~kg} \cdot \mathrm{m}^{-1}$ for the $6 \mathrm{MWD}$ work, and 67 and $54 \%$ predicted for the two reference equations. All modalities of the testing were similar at predicting COPD mortality and correlated well with the 6MWD test.

In conclusion, all modalities of testing predict mortality in chronic obstructive pulmonary disease equally well. In the 6-min walk distance test, a value $<350 \mathrm{~m}$ is associated with increased mortality and should be regarded as abnormal.

KEYWORDS: Chronic obstructive pulmonary disease, 6-min walk distance test, mortality, reference equations

hronic obstructive pulmonary disease (COPD) ranks as one of the leading causes of mortality and is predicted to become the number one cause of respiratoryrelated disability in the world by 2020 [1-3]. The inability to perform everyday activities due to exercise intolerance affects many COPD patients and is associated with poor health-related quality of life $[4,5]$ and decreased survival $[6,7]$. Targeting disability has become one of the main goals of the comprehensive management of COPD through interventions that improve the functional status of patients with this disease $[3,8]$.

The impairment in functional status affecting COPD patients is likely multifactorial, probably reflecting respiratory and nonrespiratory expressions of the disease. However, it is clear, that impaired exercise capacity better reflects the overall compromise of patients with COPD than markers that only reflect the physiological impairment of lung function, including the forced expiratory volume in one second (FEV1) in particular, as disease severity increases. CASANOVA et al. [9] have recently demonstrated that in advanced Global initiative for chronic Lung Disease (GOLD) stages of COPD, patients show a greater loss in exercise capacity than on
FEV1 \% predicted. Indeed, several studies $[6,10$, 11] have described a better association between exercise performance and mortality than with FEV1 in this disease.

The utility of the 6-min walk distance (6MWD) test to assess the functional status of patients with COPD is well established. Since its introduction [12], this test has proved to be easy to perform, reliable, inexpensive and amenable to standardisation [13, 14]. Several reference equations have been developed for healthy adults in an attempt to determine normal values for this test $[15,16]$. CARTER et al. have also proposed using 6MWD work (6MWDW) as an improved outcome measure for the $6 \mathrm{MWD}$ test. The $6 \mathrm{MWDW}$ is the product of the distance walked by patients and their body weight in $\mathrm{kg}$. The application of the two most widely used of these equations (one from USA and one from Europe), as well as the proposed method by CARTER et al. [17], to a large population of patients with COPD, and their validation using mortality as the main outcome became the purpose of the present study. The present authors aimed to compare all tests and aimed to identify the critical threshold values for the different methods of expressing the aforementioned 6MWD results, which have a close association with mortality.

\section{AFFILIATIONS}

*Bay Pines Veterans Affairs Health

Care System, Bay Pines, FL, and

${ }^{\S}$ St. Elizabeth's Medical Center,

Boston, MA, USA.

\#Nuestra Señora de la Candelaria University Hospital, Tenerife, and

"Miguel Servet Hospital, Zaragoza, Spain.

+University of Montevideo,

Montevideo, Uruguay.

${ }^{f}$ Caracas University Hospital,

Caracas, Venezuela.

CORRESPONDENCE

C.G. Cote

10000 Bay Pines Boulevard

Bay Pines

$\mathrm{FL}$

33744 USA

Fax: 17273191090

E-mail: claudia.cote@va.gov

Received:

August 102007

Accepted after revision:

October 182007

STATEMENT OF INTEREST

None declared. 
TABLE 1 Baseline patient characteristics shown by sex at the time of entry into the study

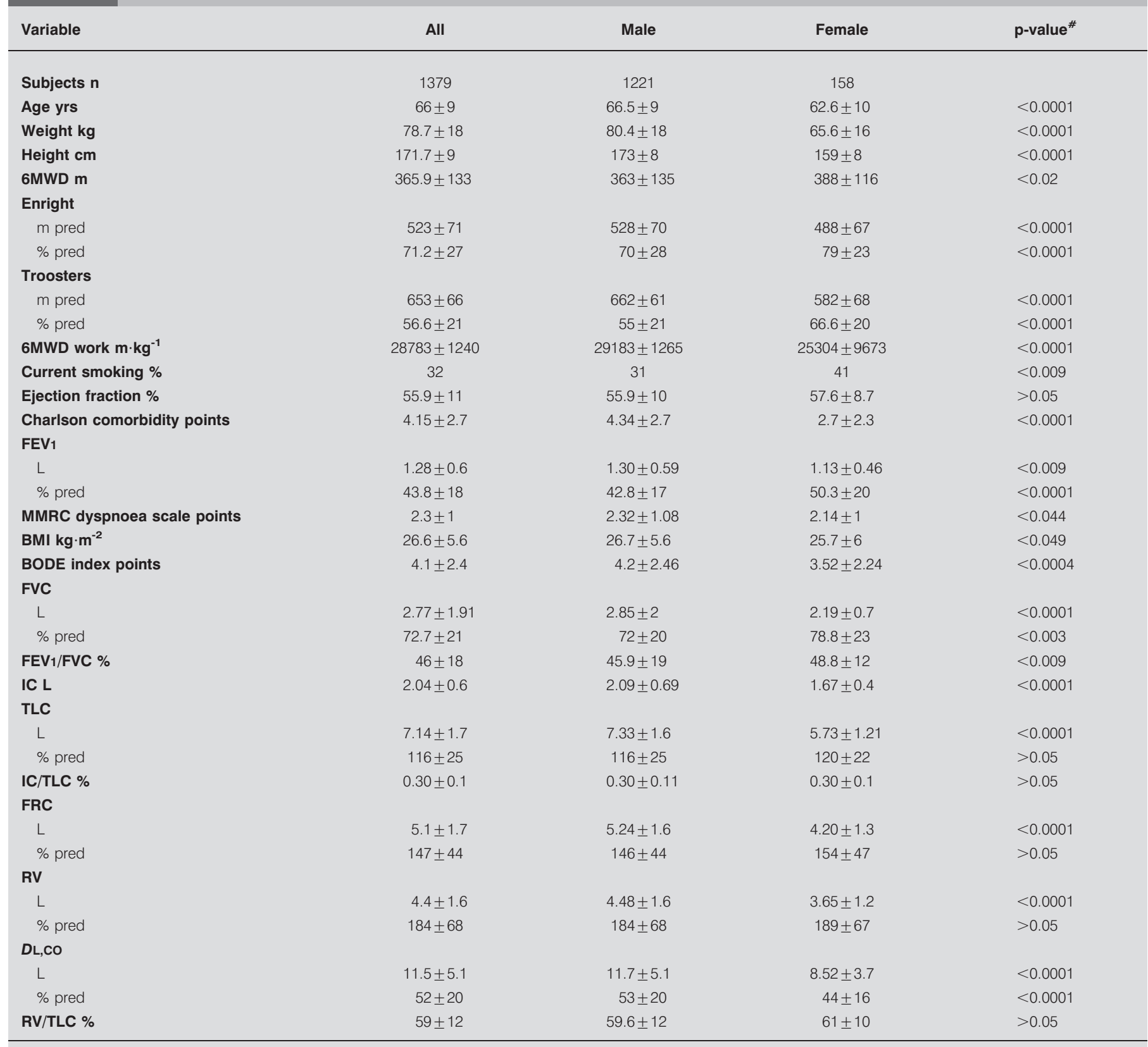

Data are presented as mean \pm SD unless otherwise stated. 6MWD: 6-min walk distance; \% pred: \% predicted; FEV1: forced expiratory volume in one second; MMRC Modified Medical Research Council; BMI: body mass index; BODE: Body mass index, Obstruction, Dyspnoea, Exercise capacity; FVC: forced vital capacity; IC inspiratory capacity; TLC: total lung capacity; FRC: functional residual capacity; RV: residual volume; $D L, C O$ : diffusing capacity of the lung for carbon monoxide. ${ }^{\#}$ : $p$-value between males and females.

\section{METHODS}

\section{Patients}

A total of 1,379 patients with a wide range of COPD stages, as accepted by the American Thoracic Society (ATS) [18], were recruited into an observational study between January 1997 and September 2004, and followed until July 2007 at several of the BODE (Body mass index, airflow Obstruction, Dyspnoea and Exercise capacity index) study sites. Inclusion/exclusion criteria have been previously published [19]. The protocol was approved by the institutional review board of each institution and all patients signed a consent form. Patients completed an evaluation within 6 weeks of enrolment and continued to be followed thereafter at 6-month intervals until July 2007 or until death. Data for mortality was confirmed by reviewing the medical records and by contacting patients' next of kin in every site. 


\begin{tabular}{|c|c|c|c|}
\hline \multirow[t]{3}{*}{ TABLE 2} & \multicolumn{3}{|c|}{$\begin{array}{l}\text { Causes of death and performance in the } 6 \text {-min } \\
\text { walk distance (6MWD) test }\end{array}$} \\
\hline & \multicolumn{3}{|c|}{ Patients' 6MWD group } \\
\hline & $<350 \mathrm{~m}$ & $>350 \mathrm{~m}$ & All patients \\
\hline Subjects $n$ & 559 & 820 & 1379 \\
\hline 6MWD m & $233 \pm 85$ & $457 \pm 70$ & $366 \pm 134$ \\
\hline Mortality & $369(66)$ & $254(31)$ & $623(45)$ \\
\hline \multicolumn{4}{|c|}{ Causes of death } \\
\hline COPD & $222(60)$ & $94(37)$ & $316(51)$ \\
\hline Lung cancer & $42(11)$ & $50(20)$ & $92(15)$ \\
\hline Other & $105(28)$ & $110(43)$ & $215(34)$ \\
\hline
\end{tabular}

Data are presented as mean \pm SD or $n(\%)$, unless otherwise stated. COPD: chronic obstructive pulmonary disease.

\section{Measurements}

Demographic information and smoking history were collected. Pulmonary function tests were obtained according to ATS guidelines [20]. Spirometry, lung volumes and diffusing capacity were also measured. The 6MWD was performed following ATS guidelines [14] and the 6MWD \% pred was calculated by using the reference equations provided by ENRIGHT and SHERRILL [15] and TROOSTERS et al. [16] for males and females. In order to calculate the 6MWDW, the distance walked by the patient in metres was multiplied by the weight of the patient in $\mathrm{kg}$ [17]. Dyspnoea was assessed using the Modified Medical Research Council (MMRC) dyspnoea scale [21]. To determine the degree of comorbidity the validated Charlson's index [22] was used.

\section{Reference equations}

The reference equations for males (1) and females (2), respectively, provided by ENRIGHT and SHERILL [15] are:

$$
\begin{aligned}
& 6 \mathrm{MWD}=(7.57 \times \text { height }(\mathrm{cm}))-(5.02 \times \text { age }(\mathrm{yrs}))- \\
& (1.76 \times \text { weight }(\mathrm{kg}))-309 \mathrm{~m} \\
& 6 \mathrm{MWD}=(2.11 \times \text { height }(\mathrm{cm}))-(5.78 \times \text { age }(\mathrm{yrs}))- \\
& (2.29 \times \text { weight }(\mathrm{kg}))-667 \mathrm{~m}
\end{aligned}
$$

and the reference equation for males and females by TROOSTERS et al. [16] is:

$$
\begin{aligned}
& 6 \text { MWD pred }=218+(5.14 \times \text { height }(\mathrm{cm})-5.32 \times \text { age }(\mathrm{yrs}))- \\
& (1.8 \times \text { height }(\mathrm{cm}))+(51.31 \times \operatorname{sex})
\end{aligned}
$$

where $\operatorname{sex}=1$ for males and 0 for females.

\section{Statistical analysis}

Normally distributed variables are reported as mean \pm SD. The differences in physical characteristics, pulmonary function test and exercise parameters were evaluated using unpaired t-tests. Comparison of 6MWD between patients with terminal COPD and those dying from other terminal diseases was performed using ANOVA. Pearson's correlation coefficients were obtained between different variables and mortality and between 6MWD, and 6MWDW and \% pred by ENRIGHT and SHERRILl [15] and TroOsTERs et al. [16]. For diagnostic analysis of the different modalities of testing, receiver operating

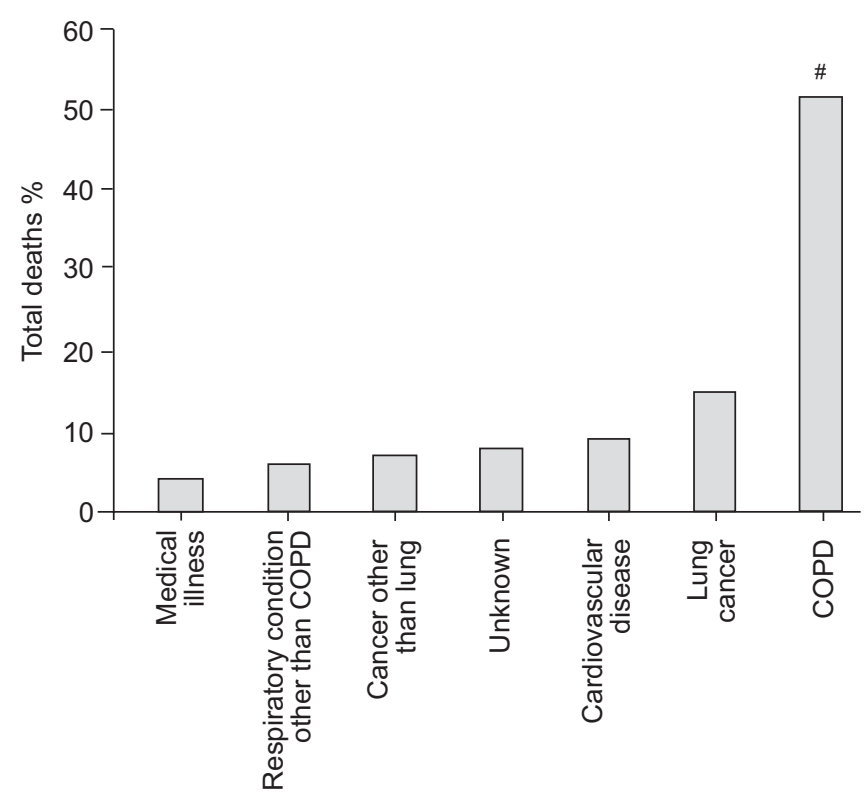

Cause of death

FIGURE 1. Mortality outcomes over the study period. COPD: chronic obstructive pulmonary disease. The 6-min walk distance (6MWD; mean $\pm \mathrm{SD}$ ) at entry into the study for each cause of death were: $353 \pm 109 \mathrm{~m}$ for medical illness; $359 \pm 129 \mathrm{~m}$ for respiratory disease other than COPD; $349 \pm 124 \mathrm{~m}$ for cancer other than lung; $326 \pm 116 \mathrm{~m}$ for unknown reasons; $328 \pm 106 \mathrm{~m}$ for cardiovascular disease; $366 \pm 130 \mathrm{~m}$ for lung cancer; and $268 \pm 136 \mathrm{~m}$ for COPD. * : 6MWD was significantly different $(p<0.00005)$ to other causes of death.

characteristic (ROC) curves were used in order to assess the thresholds with the best sensitivity and specificity to predict mortality.

\section{RESULTS}

A total of 1,379 patients with COPD aged 39-91 yrs were included in the present study. Patients were followed for $55 \pm 29$ months (range 1-150 months) or until death. The majority of patients had symptomatic COPD. FEV1 \% pred ranged $9-93 \%$ and $\mathrm{FEV} 1 /$ forced vital capacity (FVC) from 16$70 \%$. In total $<4 \%$ of the patients were in stage I COPD according to the ATS/European Respiratory Society/GOLD guidelines, 30\% were in stage II, $41 \%$ were in stage III and $25 \%$ were in stage IV. Their 6MWD ranged $24-771 \mathrm{~m}$. The baseline characteristics are shown in table 1.

\section{Mortality}

There were 623 deaths. In total $316(51 \%)$ of deaths were directly related to COPD, $40(6.4 \%)$ were of respiratory origin other than COPD, $92(14.7 \%)$ were due to lung cancer, 56 $(8.9 \%)$ to cardiovascular disease, $44(7 \%)$ to malignancies other than lung cancer, $27(4.3 \%)$ to various medical illnesses and in $48(7.7 \%)$ cases, the cause of death could not be determined. The mortality rates and the different causes of death are shown in table 2 with patients classified into two groups according to $6 \mathrm{MWD}>$ or $<350 \mathrm{~m}$. COPD mortality was much higher for patients walking $<350 \mathrm{~m}$. Non-COPD causes of death were higher among patients with preserved exercise capacity. Using ANOVA for inter-group comparisons, the mean 6MWD of patients who died as a result of COPD $(268 \pm 136 \mathrm{~m})$ was 


\begin{tabular}{lcccc} 
TABLE 3 & $\begin{array}{l}\text { Receiver operating curve analysis for the best } \\
\text { sensitivity and specificity } \\
\text { to predict survival }\end{array}$ \\
& $\begin{array}{c}\text { Threshold } \\
\text { value }\end{array}$ & $\begin{array}{c}\text { Specificity } \\
\%\end{array}$ & $\begin{array}{c}\text { Sensitivity } \\
\%\end{array}$ & AUC \\
\hline Test & 350 & 70.3 & 68.3 & 0.754 \\
& 25000 & 69.9 & 69.5 & 0.771 \\
6MWD m & 67 & 67.1 & 67.1 & 0.745 \\
6MWD work m·kg ${ }^{-1}$ & 54 & 69.1 & 67.5 & 0.753 \\
Enright \% pred & & & & \\
Troosters \% pred & 54 &
\end{tabular}

AUC: area under the curve; 6MWD: 6-min walk distance; \% pred: \% predicted.

significantly different from that of patients dying from any other cause $(348 \pm 121 \mathrm{~m})$ as shown in figure 1 .

\section{Receiver operating characteristic curves}

Using ROCs, the threshold values with the best specificity and sensitivity to predict mortality were determined for the reference equations, $6 \mathrm{MWDW}$ and $6 \mathrm{MWD}$ test. The results are shown in table 3 . The area under the curve was very similar for all four modalities of testing. Values below the thresholds were considered as abnormal.

\section{Enright's reference equation}

The threshold value for the Enright's equation was $67 \%$. A total of $560(40.6 \%)$ patients were below this threshold, 612 (44.3\%) fell between $67-100 \%$ of normal and $206(15 \%)$ patients exceeded $100 \%$ of their predicted walk. Overall mortality of patients below the critical threshold was $64.2 \%(n=360)$. A total of $212(37.7 \%)$ deaths were due to COPD. Conversely, 263 $(31.7 \%)$ deaths were seen in patients above the critical threshold and, of these, 103 (12.4\%) deaths were due to COPD.

\section{Troosters' reference equation}

The threshold value for Troosters' equation was $54 \%$. In total, $563(40.5 \%)$ patients were below this level, $612(58 \%)$ patients fell between $54-100 \%$ pred and only $10(0.7 \%)$ patients exceeded $100 \%$ of their predicted walk. The mortality in patients below the critical threshold was $65.7 \%(\mathrm{n}=370)$. A total of $218(38.7 \%)$ patients died from COPD. Among the 816 $(58.7 \%)$ patients with normal exercise capacity there were 253 (31\%) deaths and $98(12 \%)$ were due to COPD.

\section{MWD work}

The threshold valued identified for the 6MWD work was $25,000 \mathrm{~kg} \cdot \mathrm{m}^{-1}$. Using this value, $545(39.2 \%)$ patients were below the critical threshold. All cause mortality among these patients was $65.5 \%(n=357)$ and COPD mortality was $40.5 \%$ $(\mathrm{n}=221)$. Overall mortality among the 844 patients with values above the threshold was $31.5 \%(n=266)$. A total of $95(11.2 \%)$ patients died from COPD.

\section{MWD test}

The threshold value for the 6MWD test was $350 \mathrm{~m}$. A total of 559 (40.2\%) patients were below this threshold and the observed mortality among these patients was $66 \%(n=369)$. COPD mortality was $39.7 \%(n=222)$. Mortality in patients above the

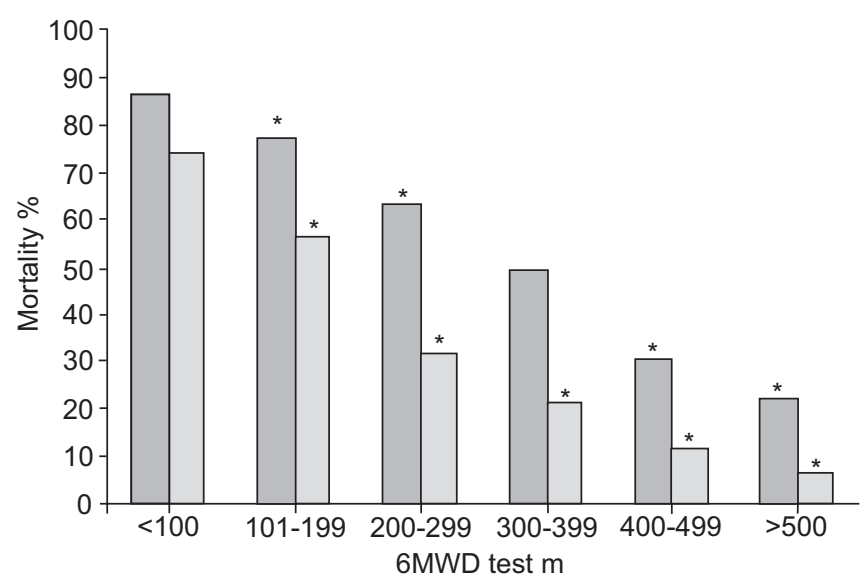

FIGURE 2. All-cause and chronic obstructive pulmonary disease (COPD) mortality in COPD patients stratified by $100 \mathrm{~m}$ in the performance of the 6-min walk

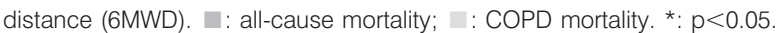

critical threshold was $30.6 \%(\mathrm{n}=254)$, and $94(11.3 \%)$ patients died from COPD.

Comparison of patients above and below the different thresholds are shown in table 2. An exponential increase was noted in all-cause mortality for every $100 \mathrm{~m}$ decrease in the $6 \mathrm{MWD}$ test. The results are shown in figure 2.

\section{Correlations with mortality}

Pearson's correlation coefficients were used to investigate the relationship between all-cause mortality and COPD mortality with exercise performance in all patients and according to sex. When all patients were included in the analysis, similar correlations between all-cause mortality and COPD mortality were found, with all type of evaluations. Higher correlations were seen between all-cause mortality and female sex for all modalities of testing. The results are shown in table 4 .

Kaplan-Meier survival analysis is shown in figure 3. No significant differences between the tests was found. The best Chi-squared value was seen with the 6MWD work.

\begin{tabular}{|c|c|c|c|c|c|}
\hline \multirow[t]{2}{*}{ TABLE 4} & \multicolumn{5}{|c|}{$\begin{array}{l}\text { Correlation coefficients for all-cause mortality } \\
\text { and chronic obstructive pulmonary disease } \\
\text { (COPD) mortality for all patients and according } \\
\text { to sex }\end{array}$} \\
\hline & & Enright & Troosters & 6MWD & $\begin{array}{c}\text { 6MWD } \\
\text { work }\end{array}$ \\
\hline \multicolumn{6}{|c|}{ All-cause mortality } \\
\hline All & & -0.358 & -0.388 & -0.396 & -0.388 \\
\hline Males & & -0.339 & -0.358 & -0.382 & -0.412 \\
\hline Females & & -0.496 & -0.499 & -0.495 & -0.449 \\
\hline \multicolumn{6}{|c|}{ COPD mortality } \\
\hline All & & -0.378 & -0.395 & -0.398 & -0.395 \\
\hline Males & & -0.369 & -0.386 & -0.395 & -0.411 \\
\hline Females & & -0.412 & -0.403 & -0.394 & -0.381 \\
\hline
\end{tabular}


Pearson's correlation coefficients revealed an excellent correlation between the 6MWD, Troosters \% pred $(\mathrm{r}=0.96)$, Enright \% pred $(\mathrm{r}=0.93)$, and a slightly less significant correlation with 6MWD work $(\mathrm{r}=0.83)$. ROC curves (fig. 4) showed all tests to have a similar discriminatory diagnostic capability for mortality in COPD patients. The area under the curve (AUC) for: 6MWD was 0.75; for 6MWD work, 0.77; for Enright \% pred, 0.74; and for Troosters \% pred, 0.75 . The differences between groups were not statistically significant.

\section{Discussion}

The present study has several important findings. First, it has been found that the absolute value of $6 \mathrm{MWD}$ is as good a predictor of mortality in patients with COPD as values normalised by reference equations. Secondly, a $6 \mathrm{MWD}$ value of $<350 \mathrm{~m}$ can be used as a threshold for poor prognosis. ROCs are considered the optimal method to determine the best performance for a diagnostic test, based on their best sensitivity and specificity. Threshold values of clinically significant abnormality were identified for published reference equations and for the 6MWD work and the 6MWD test and it was found
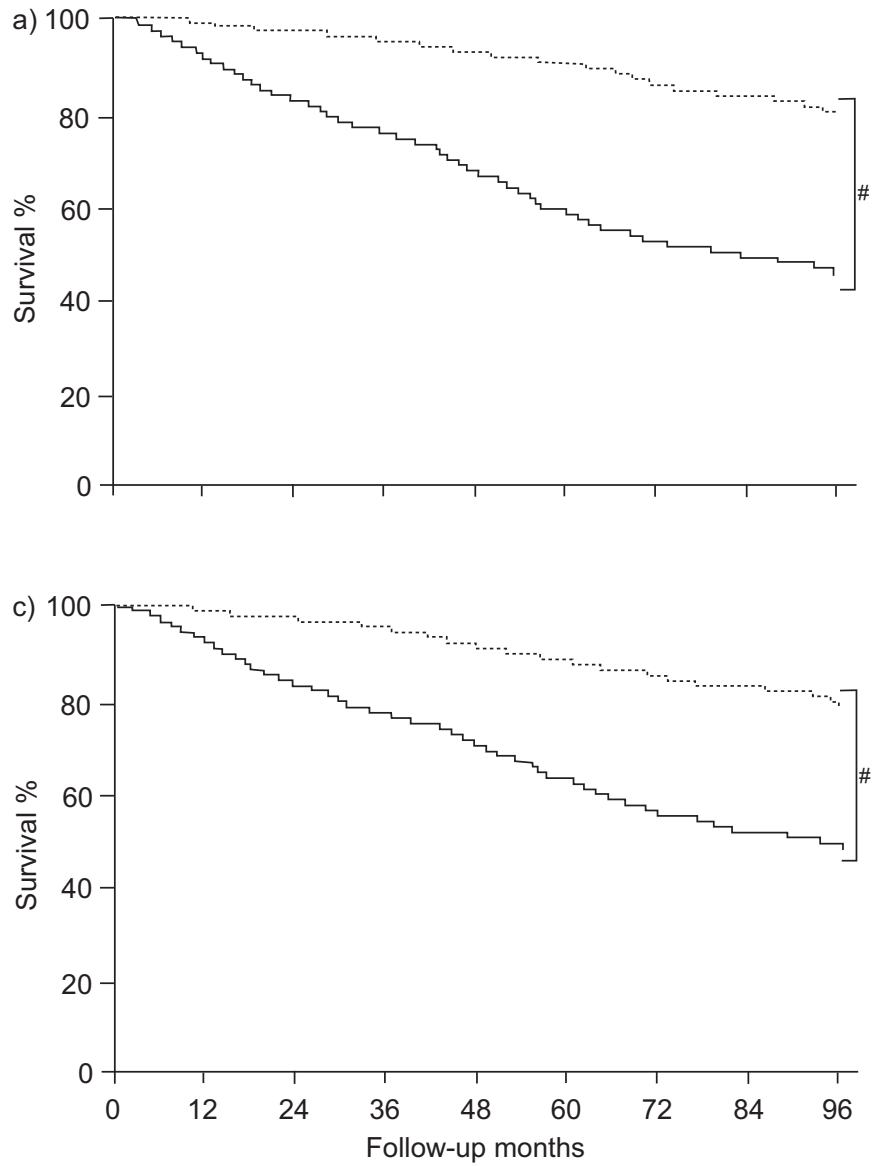

that they predicted mortality in COPD in almost an identical way (table 3).

Thirdly, the present study has shown that there is an increased correlation between mortality and female sex for all tests, which suggests that poor exercise performance in females might carry an ominous prognosis. As seen in table 4, the correlation between 6MWD and mortality in females was $r=-0.49, p<0.0001$ versus $r=-0.38, p<0.0001$ in males. Sexrelated differences in patients with COPD need closer consideration.

COPD is a disease that impairs functional capacity. However, the degree of exercise intolerance as measured by the 6MWD test varies widely even among patients with similar airflow limitation. This was evident in large clinical trials such as that of patients enrolled for lung volume reduction surgery [23], who by design had a narrow range of airflow limitation but a wide range of exercise performance. The exact reason for exercise limitation in COPD is not fully understood but appears to be somewhat independent of FEV1. In the majority of patients with COPD, dyspnoea is a main limiting factor [24],

b)

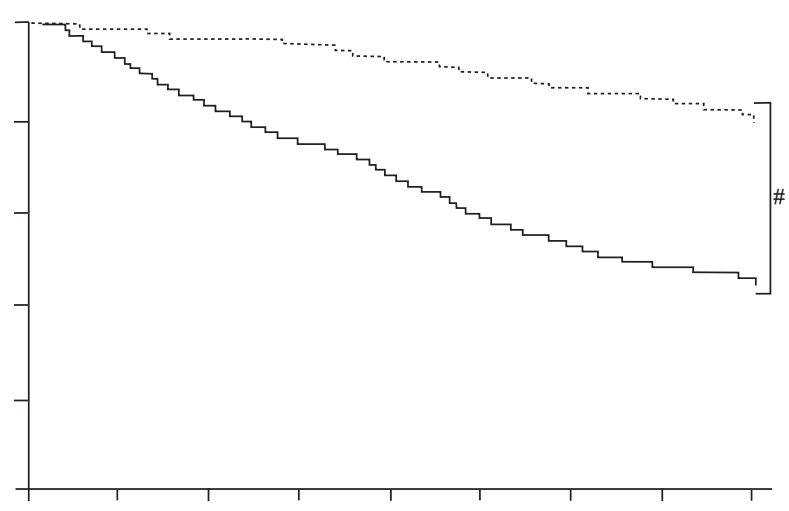

d)

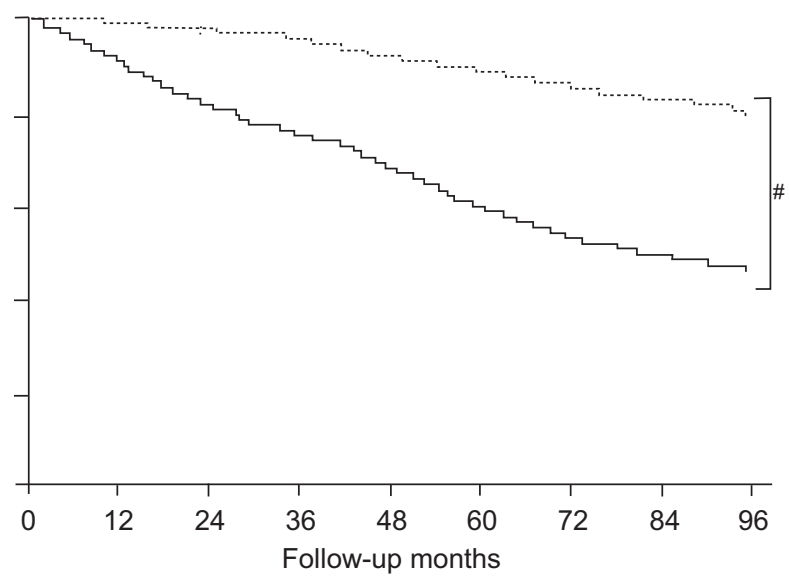

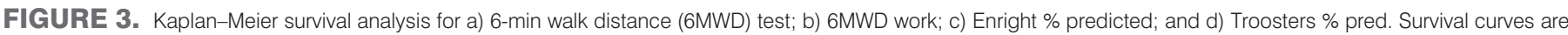

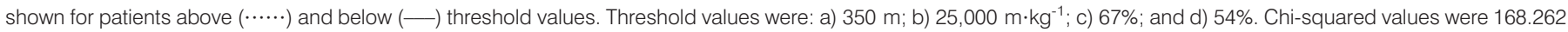

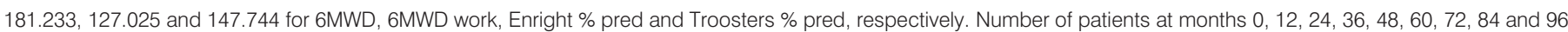

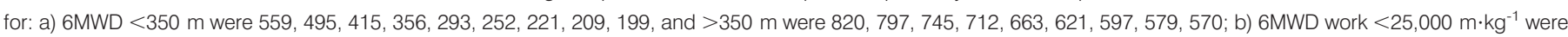

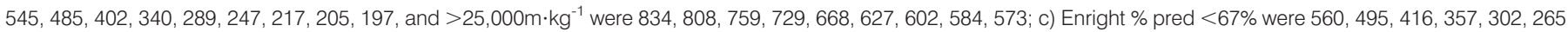

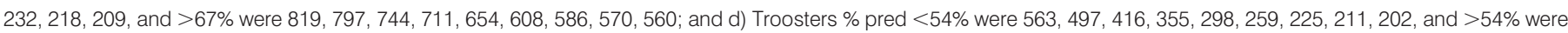
$816,795,744,713,658,614,593,577$ and 567; respectively. ${ }^{*}: p<0.00005$. 

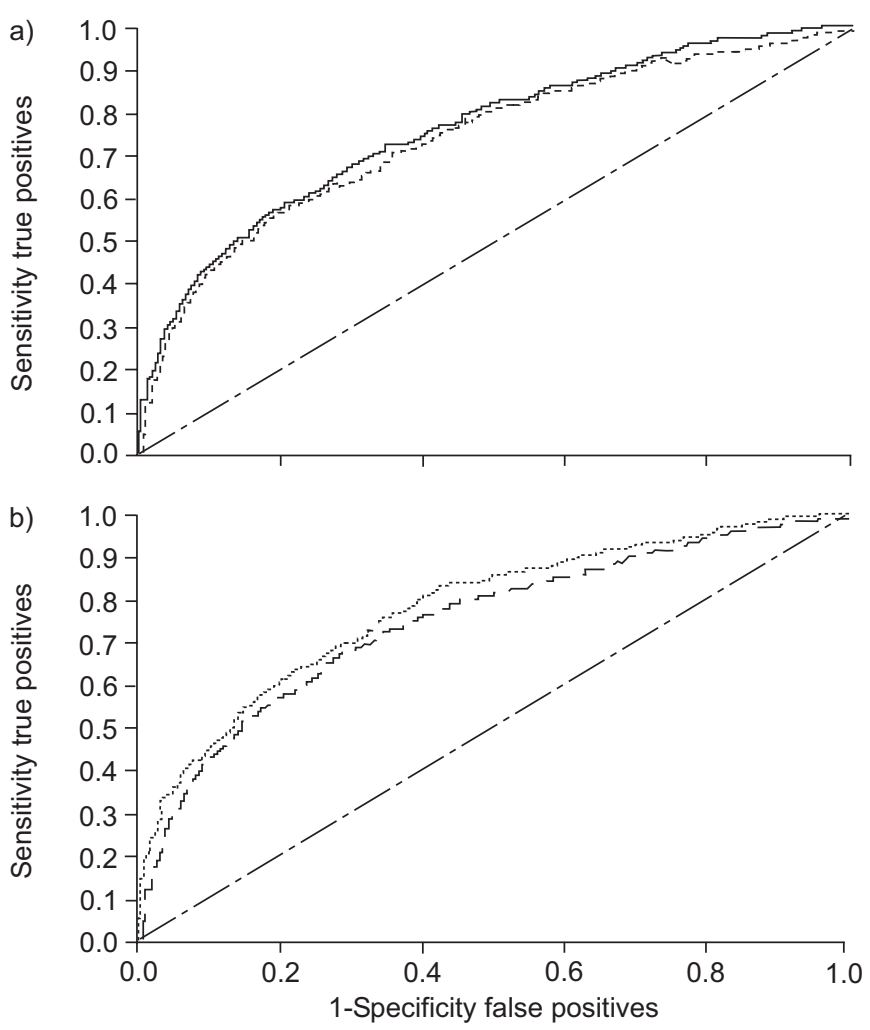

FIGURE 4. Receiver operating characteristic curves show great similarity between all modalities of testing. The best area under the curve was found with the 6-min walk distance (6MWD) test work, although there was no statistical significant difference between the groups. —_: Troosters \% predicted; ----: Enright \% pred; …: 6MWD work; — - - 6MWD.

likely related to hyperinflation [25, 26], airflow limitation [27] and impairment in diffusing capacity [28]. In addition, skeletal muscle dysfunction has also been implicated in the genesis of exercise limitation among patients with COPD [29]. The muscle of COPD patients shows structural and metabolic abnormalities, not seen in normal patients of similar age [3032]. Whatever the exact reasons for exercise limitation, the evaluation of exercise capacity using the 6MWD in patients with COPD helps assess disease severity. Furthermore, identifying levels of exercise impairment helps with the characterisation of these patients and assists with the referral to programmes such as pulmonary rehabilitation, lung reduction surgery or lung transplantation.

Most authors agree that 6MWD is a practical field test but its correct interpretation is more debatable [33]. Studies have used the absolute value in metres to determine its prognostic ability or its responsiveness to pulmonary rehabilitation [7] or lung reduction surgery [23]. However, it is well known that the $6 \mathrm{MWD}$ is influenced by age, sex and height. Indeed, the two studies validated herein, have provided reference equations based on the testing of normal individuals and then expressed the observed results as a percentage of predicted normal [15, 16]. Interestingly, both reference values, although obtained through different methodologies, performed similarly at predicting mortality in COPD, indicating that at least for males, the equations have similar behaviour. Although the number of female patients in the present study was relatively small $(n=158)$, they were found to have a higher 6MWD compared with males. The female patients were compared to an equal number of male patients $(n=160)$, matched by FEV $1 \%$ $(50 \pm 12)$ and age. Females walked $12-15 \%$ more according to reference equations and $\sim 35 \mathrm{~m}$ more according to the 6MWD. This finding is similar to that found in the unmatched analysis (females $n=158$, males $n=1221$ ) but needs to be tested in a larger population of female patients with COPD. This finding may explain the lower mortality observed among females compared with males (all-cause mortality 22 versus 48\%, $\mathrm{p}<0.002$; COPD mortality 12 versus $24 \%$, $\mathrm{p}<0.007$ ). Conversely, the walking distance of males dying from COPD $(252 \pm 131 \mathrm{~m})$ was very similar to that of females dying from COPD $(264 \pm 118 \mathrm{~m})$. However, the observed per cent predicted by reference equations for males (Enright $=48 \%$, Troosters $=38 \%$ ) was significantly lower than the observed per cent predicted among females who died (Enright $=54 \%$, Troosters $=45 \%$ ). Taken together, these findings suggest that a lower 6MWD in females might confer a worse prognosis than in males.

The present authors believe that, this is the first large study of a well characterised population of patients with COPD that applies and validates reference equations, determines values of clinical significance and describes the association between the performance on these tests and mortality over a long observational period. Previous reports included a smaller number of patients and a shorter time of follow-up. In the present study, the value of the 6MWD as a surrogate for survival has been further demonstrated. The present study confirms the threshold of clinical relevance for the 6MWD, as described in the original BODE study [19]. As shown in table 3, this threshold has similar sensitivity and specificity for mortality as reference equations and 6MWD work, and an almost linear increase in mortality as the walking distance decreases by $100 \mathrm{~m}$ (fig. 2).

The present study has several limitations; the most important is the small number of females included in the study. Thus, the generalisation of these results to female patients with COPD may not fully apply and remains to be validated in studies including a much larger number of females. Additionally, the population included is primarily that of patients attending pulmonary clinics. This may bias toward patients with more symptomatic disease and it remains to be proven that the conclusions are extensive to the COPD population at large. Conversely, the long-term follow-up and the relatively large population included do suggest that the conclusions may be applicable to the majority of patients in whom an evaluation of exercise capacity may be of clinical value.

In summary, the present study shows that the distance walked during a 6-min walk distance test by patients with chronic obstructive pulmonary disease is as good a predictor of mortality as values normalised by reference equations and by the 6-min walk distance work. The present authors believe that the application of reference equations may be justified for the scientific interpretation of exercise performance. However, they add complexity to a test that remains grossly underutilised. Facilitating the interpretation of the test could influence implementation by the practitioner. The present authors believe that a 6-min walking distance test adds 
important independent information to the routine evaluation of patients with symptomatic chronic obstructive pulmonary disease and should be incorporated in the regular evaluation of these patients. If the value is $>350 \mathrm{~m}$, there is less need for close observation. Conversely, a value lower than this threshold identifies patients at higher risk for death and therefore candidates for closer observation and for possible therapies, such as pulmonary rehabilitation or lung volume reduction.

\section{REFERENCES}

1 Murray CJ, Lopez AD. Mortality by cause for eight regions of the world: Global Burden of Disease Study. Lancet 1997; 349: 1269-1276.

2 World Health Organization. World Health Report, 2000. Geneva, World Health Organization, 2000.

3 Pauwels RA, Buist AS, Calverley PM, Jenkins CR, Hurd SS. GOLD Scientific Committee: Global strategy for the diagnosis, management and prevention of chronic obstructive pulmonary disease. NHLBI/WHO Global Initiative for Chronic Obstructive Lung Disease (GOLD) Workshop summary. Am J Respir Crit Care Med 2001; 163: 1256-1276.

4 Engström CP, Persson LO, Larsson S, Rydén A, Sulliwan M. Functional status and well being in chronic obstructive pulmonary disease with regard to clinical parameters and smoking: a descriptive and comparative study. Thorax 1996; 51: 825-830.

5 Jones PW, Quirk FH, Baveystock CM, Littlejohns P. A selfcomplete measure of health status for chronic airflow limitation: the St. George's Respiratory Questionnaire. Am Rev Respir Dis 1992; 145: 1321-1327.

6 Pinto-Plata VM, Cote C, Cabral H, Taylor J, Celli BR. The 6min walk distance: change over time and value as a predictor of survival in severe COPD. Eur Respir J 2004; 23: 28-33.

7 Gerardi DA, Lovett L, Benoit-Connors ML, Reardon JZ, ZuWallack RL. Variables related to increased mortality following out-patient pulmonary rehabilitation. Eur Respir J 1996; 9: 431-435.

8 Lacasse Y, Brosseau L, Milne S, et al. Pulmonary rehabilitation for chronic obstructive pulmonary disease. Cochrane Database Syst Rev 2003; 4: CD003793.

9 Casanova C, Cote CG, Marin JM, et al. The 6-minute walking distance: long-term follow up in patients with COPD. Eur Respir J 2007; 29: 535-540.

10 Szekely LA, Oelberg DA, Wright C, et al. Preoperative predictors of operative morbidity and mortality in COPD patients undergoing bilateral lung volume reduction surgery. Chest 1997; 111: 550-558.

11 Oga T, Nishimura K, Tsukino M, Sato S, Hajiro T. Analysis of the factors related to mortality in chronic obstructive pulmonary disease: role of exercise capacity and health status. Am J Respir Crit Care Med 2003; 167: 544-549.

12 McGavin CR, Gupta SP, McHardy GJ. Twelve-minute walking test for assessing disability in chronic bronchitis. Br Med J 1976; 1: 822-823.

13 Butland RJ, Pang J, Gross ER, Woodcock AA, Geddes DM. Two-, six-, and 12-minute walking tests in respiratory disease. Br Med J (Clin Res Ed) 1982; 284: 1607-1608.

14 ATS Committee on Proficiency Standards for Clinical Pulmonary Function Laboratories, ATS Statement: guidelines for the six-minute walk test. Am J Respir Crit Care Med 2002 166: 111-117.

15 Enright PL, Sherrill DL. Reference equations for the sixminute walk in healthy adults. Am J Respir Crit Care Med 1998; 158: 1384-1387.

16 Troosters T, Gosselink R, Decramer M. Six minute walking distance in healthy elderly subjects. Eur Respir J 1999; 14: 270-274.

17 Carter R, Holiday D, Nwasuruba C, Stocks J, Grothues C, Tiep B. 6-minute walk work for assessment of functional capacity in patients with COPD. Chest 2003; 123: 1408-1415.

18 Celli BR, MacNee W, ATS/ERS Task Force. Standards for the diagnosis and treatment of patients with COPD: a summary of the ATS/ERS position paper. Eur Respir J 2004; 23: 932-946.

19 Celli BR, Cote CG, Marin JM, et al. The body-mass index, airflow obstruction, dyspnea and exercise capacity index in chronic obstructive pulmonary disease. New Engl J Med 2004; 350: 1005-1012.

20 Standardization of spirometry: 1994 update. American Thoracic Society. Am J Respir Crit Care Med 1995; 152: 1107-1136.

21 Mahler DA, Weinberg DH, Wells CK, Feinstein AR. The measurement of dyspnea. Contents, interobserver agreement, and physiologic correlates of two new clinical indexes. Chest 1984; 85: 751-758.

22 Charlson M, Szatrowski TP, Peterson J, Gold J. Validation of a combined comorbidity index. J Clin Epidemiol 1994; 47: 1245-1251.

23 Fishman A, Martinez F, Naunheim K, et al. A randomized trial comparing lung-volume-reduction surgery with medical therapy for severe emphysema. N Engl J Med 2003; 348: 2059-2073.

24 O'Donnell DE, Webb KA. Exertional breathlessness in patients with chronic airflow limitation. The role of lung hyperinflation. Am Rev Respir Dis 1993; 148: 1351-1357.

25 Marin JM, Carrizo SJ, Gascon M, Sanchez A, Gallego B, Celli BR. Inspiratory capacity, dynamic hyperinflation, breathlessness, and exercise performance during the 6minute-walk test in chronic obstructive pulmonary disease. Am J Respir Crit Care Med 2001; 163: 1395-1399.

26 Casanova C, Cote C, de Torres JP, et al. Inspiratory-to-total lung capacity ratio predicts mortality in patients with chronic obstructive pulmonary disease. Am J Respir Crit Care Med 2005; 171: 591-597.

27 O'Donnell DE, Lam M, Webb KA. Spirometric correlates of improvement in exercise performance after anticholinergic therapy in chronic obstructive pulmonary disease. Am J Respir Crit Care Med 1999; 160: 542-549.

28 Carlson DJ, Ries AL, Kaplan RM. Prediction of maximum exercise tolerance in patients with COPD. Chest 1991; 100: 307-311.

29 Whittom F, Jobin J, Simard PM, et al. Histochemical and morphological characteristics of the vastus lateralis muscle in patients with chronic obstructive pulmonary disease. Med Sci Sports Exerc 1998; 30: 1467-1474.

30 Gosselink R, Troosters T, Decramer M. Peripheral muscle weakness contributes to exercise limitation in COPD. Am J Respir Crit Care Med 1996; 153: 976-980. 
31 Mador MJ, Deniz O, Aggarwal A, Kufel TJ. Quadriceps fatigability after single muscle exercise in patients with chronic obstructive pulmonary disease. Am J Respir Crit Care Med 2003; 168: 102-108.

32 Bernard S, LeBlanc P, Whittom F, et al. Peripheral muscle weakness in patients with chronic obstructive pulmonary disease. Am J Respir Crit Care Med 1998; 158: 629-634.

33 Redelmeier DA, Bayoumi AM, Goldstein RS, Guyatt GH. Interpreting small differences in functional status: the Six Minute Walk test in chronic lung disease patients. Am J Respir Crit Care Med 1997; 155: 1278-1282. 